\title{
Factors associated with constipation in a community based sample of people aged 70 years and over
}

\author{
A John Campbell, Wendy J Busby, Caroline C Horwath
}

\author{
Abstract \\ Study objective-The aim was to \\ determine the prevalence and factors \\ associated with constipation in elderly \\ people.
}

Design-The study was a survey involving administration of a structured questionnaire, an interview, and a dietary assessment.

Setting-The survey was community based and the population studied was drawn from the practice records of all five general practitioners serving a rural township of 13500 people.

Participants-778 (91.8\%) of the 856 people aged 70 years and over registered with the five practitioners took part.

Main results -174 subjects had symptoms of infrequent bowel motions or frequent straining at stool or used laxatives regularly. Of this group, 34 had a bowel motion only every $3 \mathrm{~d}$ or less frequently and were considered to have constipation. Analysis of this subgroup showed that constipation was more common in women than men, increased with age, and was associated with the use of constipating drugs. Those whose bowels moved infrequently were a more frail group who were less physically active. Low intakes of dietary fibre, fruit, vegetables, bread and cereals, or fluid were not associated with an increased occurrence of constipation. There were 151 subjects who felt they were moderately constipated, but who had a bowel motion at least every $2 \mathrm{~d}$. These people were more likely than the rest of the sample to use laxatives $(55 \cdot 6 \%)$, were more likely to take food for their bowels, to take hynoptics, and to regard their health as poor.

Conclusions-About one third of people aged 70 years and over have some bowel problem such as infrequency, straining at stool, or frequent laxative use. Most modify their diet accordingly but laxative use remains high.

University of Otago Medical School, PO Box 913, Dunedin, New Zealand: Department of Medicine A J Campbell W J Busby Department of Human Nutrition C C Horwath

Correspondence to: Professor Campbell

Accepted for publication June 1992 than three times per week. ${ }^{3}$ Yet the complications from constipation, such as perianal problems and faecal impaction and overflow, are real enough.

Alternatively, the paucity of epidemiological data may result from the difficulties of investigating constipation. The problem is difficult to define and there may be considerable differences in what the investigators and the subjects consider as constipation. There is also the problem of self treatment. People who consider themselves "constipated" may take laxatives, modify their diet and have regular bowel motions, so that when investigating factors associated with constipation it is difficult to know whether they were ever constipated.

We have investigated the factors associated with constipation in a community based sample of 782 people 70 years and over. To overcome the methodological difficulties we have used a rigorous definition of constipation and have excluded from the comparison group those who take regular laxatives. We have also investigated those who regard themselves as constipated but who have normal bowel frequency.

\section{Methods}

Mosgiel is a rural township of 13500 people situated just south of Dunedin, New Zealand. It has been the centre for an ongoing series of community based epidemiological studies of disorders in old age. The investigation of constipation was an additional component of stage II of the project which is a longitudinal study of risk factors for cardiovascular disease.

Mosgiel is served by five family practitioners based at the Mosgiel health centre. Comparison with the electoral roll showed that $94 \%$ of the people living in the area were registered with the centre. Names, ages, and addresses of those 70 years and over on 1 August 1988 were obtained from the health centre records. The sample frame included those in the community and those in residential homes but did not include any person in continuing hospital care. The proportion of people living in residential homes was similar to that in the country as a whole.

All subjects were seen in their homes by the research nurse who administered the initial questionnaire. This included questions on bowel habit, investigating frequency of bowel motions, straining, laxative use, food modification, and feelings of constipation. The subjects were left with a food frequency questionnaire to complete. This questionnaire was designed specifically for use with elderly people. It included a list of some 120 food and drink items and has been shown by comparison with five $2 \mathrm{~d}$ diet records to be a valid 
method for estimating both group mean and individual nutrient intakes in elderly people (Horwath CC, unpublished data). The completion of the dietary questionnaire was monitored by a nutritionist $(\mathrm{CCH})$ who assisted any subjects who were unable to complete the form. The subjects were then seen at the health centre by one of two consultant physicians (WJB, AJC) who reviewed the questionnaires.

The distributions of the variables investigated as factors likely to be associated with constipation were examined at the completion of the study and the value of each variable below which level the subjects were considered at risk of constipation was then determined.

The following variables were investigated as possible contributing factors for constipation.

(1) Sex and age, within five year age groups.

(2) Dietary variables. These included estimated dietary fibre intake as well as consumption from the main food group sources of fibre in the diet. Questions on the individual food items were used to compute variables representing the total frequency of consumption from the bread and cereal, fruit, and vegetable groups. Those subjects whose intake was less than the 10th percentile for the group as a whole were considered to have a low intake which may have contributed to constipation. Fluid intake was also measured by frequency questionnaires and again those whose intake was less than the 10th percentile were considered at risk of constipation.

(3) Poor nutritional state. This was defined as being less than the 10th percentile of the sample studied for body mass index or corrected arm muscle area or triceps skinfold thickness. The methods for measuring these variables in the Mosgiel studies have been described previously. ${ }^{4}$ (4) Physical activity. This was assessed by questionnaire and two groups were investigated as being at possible risk of constipation. Firstly, those who took part in no form of physical exercise including walking for pleasure were compared with those who did participate in some form of physical exercise at least weekly. Secondly, those who had very low levels of physical activity defined as those who played no sport, did not walk to the shops, and did not take part in any household or gardening activities were compared with the remainder.

(5) The use of constipating drugs which included anticholinergic drugs, tricyclic antidepressants, phenothiazines, verapamil, opiates, and codeine preparations was recorded.

(6) Mental state. All subjects completed the geriatric depression scale. ${ }^{5}$ The distribution of scores was reviewed at completion of the study. Those subjects who had a score equal to or greater than 14 were regarded as showing evidence of depressed mood and were compared with the remainder of the sample. Impaired cognitive function was also investigated and those who had a score of less than 24 on the minimental state questionnaire ${ }^{6}$ were considered impaired.

(7) Self care. Ability with self care activities and with instrumental activities of daily living was assessed using the scale developed by Lawton and Brody. ${ }^{7}$ Those who were able to complete only three or fewer of the eight items on the instrumental activities of daily living scale were investi- gated for increased risk of constipation. On the activities of daily living scale those who were able to complete only four or fewer of the six items of this scale were regarded as being at risk of constipation.

To determine factors that predicted constipation we divided subjects into those who were constipated and those who were not, using a rigorous definition of constipation. The group with constipation included only those subjects whose bowels moved every three days or less frequently. When using this definition of constipation, we excluded from the comparison group those who took laxatives at least weekly. Our reason for doing this was that those who were regular laxative users may have been as prone to constipation as the study group and have had the same risk factors for constipation if untreated.

We then investigated those people who considered themselves as moderately or severely constipated, but whose bowels moved regularly. The people in this group were also investigated to determine whether they had other indicators of poor subjective health including poor sleep, regular use of hypnotics or poor self rated health

Bivariate analyses using $\chi^{2}$ test were done to identify those variables which differed in distribution in the constipated and not constipated groups.

\section{Results}

From the initial sample of 856 subjects, 782 $(91.4 \%)$ agreed to participate in the study and completed both the nursing and medical assessments. Those refusing did so for a variety of reasons. Comparison with health centre records in the Mosgiel studies has shown that those refusing were not a more frail group. ${ }^{8}$ The constipation questionnaire was completed satisfactorily in 778 subjects.

The food frequency questionnaire was completed by 727 subjects ( 261 men, 466 women). In the analysis of the effects of diet on constipation, only these subjects are included. The low dietary intake scores, defined as being less than the 10th percentile for the sample as a whole were: dietary fibre less than $15 \mathrm{~g} / \mathrm{d}$; a serving of fruit eaten less than 26 times per month; a serving of vegetables eaten less than 89 times per month; bread and cereal intake less than 63 servings per month (1 slice of bread $=1$ serving). The 10 th percentile for fluid intake was 1 litre per day.

Of the 778 subjects who completed the constipation questionnaire, $496(63.8 \%)$ were women and $282(36.2 \%)$ were men with an age range of 70-102 years.

Bowel symptoms in subjects who completed the questionnaire are shown in the table. There were 174 subjects who had at least one of three factors which may have indicated constipation. Thirty four subjects moved their bowels only every three days or less frequently; 70 subjects strained at stool almost always, and 139 subjects took a laxative at least every two to three days. The need to strain at stool was more common in those with infrequent bowel movements $(41.2 \%)$ than in the remainder of the sample $(7.9 \%)\left(\chi^{2}=43.3\right.$, $\mathrm{p}<0.001)$. 
Bowel symptoms in 778 subjects 70 years and over

\begin{tabular}{|c|c|c|}
\hline & $\begin{array}{l}\text { Male } \\
(n=282) \%\end{array}$ & $\begin{array}{l}\text { Female } \\
(n=496) \%\end{array}$ \\
\hline $\begin{array}{c}\text { Bowel frequency } \\
>2 \text { per day } \\
1-2 \text { per day } \\
1 \text { per } 2 \text { days } \\
1 \text { per } 3-5 \text { days } \\
<1 \text { per week }\end{array}$ & $\begin{array}{r}3.2 \\
86 \cdot 5 \\
8 \cdot 5 \\
1 \cdot 8\end{array}$ & $\begin{array}{r}4 \cdot 4 \\
78 \cdot 4 \\
11 \cdot 3 \\
5 \cdot 2 \\
0 \cdot 6\end{array}$ \\
\hline $\begin{array}{l}\text { Do you suffer from } \\
\text { Severely } \\
\text { Moderately }\end{array}$ & $\begin{array}{l}\text { onstipation? } \\
5 \cdot 3 \\
12 \cdot 1\end{array}$ & $\begin{array}{r}8 \cdot 1 \\
17 \cdot 7\end{array}$ \\
\hline $\begin{array}{l}\text { Do you have to stra } \\
\text { when opening your } \\
\text { Almost always } \\
\text { Occasionally }\end{array}$ & $\begin{array}{l}\text { n for some time } \\
\text { owvels? } \\
9 \cdot 3 \\
44 \cdot 5\end{array}$ & $\begin{array}{r}9 \cdot 0 \\
47 \cdot 6\end{array}$ \\
\hline $\begin{array}{l}\text { Do you use a laxat } \\
\text { Daily } \\
\text { Every 2-3 days } \\
\text { Weekly }\end{array}$ & $\begin{array}{r}11 \cdot 3 \\
3 \cdot 2 \\
3 \cdot 9\end{array}$ & $\begin{array}{r}14 \cdot 3 \\
5 \cdot 4 \\
1 \cdot 4\end{array}$ \\
\hline Do you eat foods re & $\begin{array}{l}\text { ularly for your } \\
46 \cdot 1\end{array}$ & $64 \cdot 6$ \\
\hline
\end{tabular}

FACTORS ASSOCIATED WITH CONSTIPATION

Those 34 subjects whose bowels moved only every three days or less frequently were then compared with the rest. Those who took laxatives at least weekly were excluded from the comparison group.

There were significantly more women $(29 ; 7 \%)$ than men $(5 ; 2.1 \%)$ in the group suffering from constipation $\left(\chi^{2}=7 \cdot 2, p=0 \cdot 007\right)$, and the prevalence of constipation increased with age $\left(\chi^{2}=60.9\right.$, df $\left.5, p=0.005\right)$.

The group suffering from constipation was more frail, being significantly more likely to have impaired performance in instrumental activities of daily living $\left(\chi^{2}=12 \cdot 7, \mathrm{p}<0.001\right)$, and in self maintenance $\left(\chi^{2}=13.9, p<0.001\right)$. They were less likely to take any form of exercise $\left(\chi^{2}=6\right.$, $p=0.014)$, but were not more likely to have extremely low levels of physical activity.

Eight $(23.5 \%)$ of the 34 were taking constipating drugs and this was a higher proportion than the comparison group $(12 \%)\left(\chi^{2}=2.9\right.$, $\mathrm{p}=0.048)$. Women $(17.5 \%)$ were more likely than men $(9.5 \%)$ to be taking constipating drugs $\left(\chi^{2}=9 \cdot 2, p=0.002\right)$.

Subjects who were constipated were not more likely to be in the lowest decile of dietary fibre, fruit, vegetable, cereal, or fluid intake. In fact 27 $(79 \%)$ of the 34 patients suffering from constipation specifically ate foods which they felt were good for their bowels. This is a higher proportion than in the comparison group (55.6\%) $\left(\chi^{2}=7 \cdot 4, p=0.006\right)$. Men were significantly more likely to be in the lowest decile of fruit intake $(p=0.001)$ and fluid intake $(p=0.003)$, women were more likely than men to be in the lowest decile of cereal intake $(p=0.02)$.

Those who were constipated were not more likely to be depressed or have impaired cognitive function.

SUBJECTIVE CONSTIPATION

We then investigated the group who felt that they were moderately or severely constipated but whose bowels moved at least every two days. These 151 subjects were much higher users of laxatives $(55.6 \%)$ than the remaining subjects $(10.8 \%)\left(\chi^{2}=144.7, p<0.0001\right)$ and were more likely to take particular foods for their bowels $(71.1 \%)$ than the comparison group $(54.6 \%)$ $\left(\chi^{2}=13 \cdot 4, p=0.0003\right)$. In addition, eight $(21 \%)$ of the 38 men and $19(19 \%)$ of the 99 women who reported themselves to be constipated and who had completed the food frequency questionnaire, were regularly supplementing their diet with unprocessed bran. Although slightly higher, these proportions were not significantly different from those in the comparison group $13 \%$ of men and $14 \%$ of women). They were more likely to be taking hypnotics $(28.9 \%)$ than the comparison group $(19.4 \%)\left(\chi^{2}=6.36, \mathrm{p}<0.025\right)$. They were also more likely to be on constipating drugs $(21.9 \%)$ than the comparison group $(12.9 \%)$ $\left(\chi^{2}=7 \cdot 8, p=0.05\right)$. There was no significant sex difference, but there was a significant increase in constipation with age $\left(\chi^{2}=13.0,5 \mathrm{df}, \mathrm{p}=0.02\right)$. Subjects were asked to compare their health with other people their own age. A feeling of poor health compared with peers was more common in the group who were constipated $(17 \cdot 3 \%$ ) than in the comparison group $(11 \cdot 3 \%)\left(\chi^{2}=4 \cdot 1\right.$, $\mathrm{p}=0.04)$.

Those who assessed themselves as constipated were not more likely to be depressed or have impaired cognitive function.

Those who felt they were moderately or severely constipated but whose bowels moved at least every two days were asked what they understood being constipated meant. The great majority, over $90 \%$, equated constipation with bowels not opening for two days or more. If this occurred, the majority, again over $90 \%$, would then modify their diet by increasing fruit, bran, or fluid intake and/or taking a laxative or a home remedy. Only a few did nothing and "it eventually comes right". About $10 \%$ of this group felt their bowels needed to move daily and took laxatives to ensure this. They "would really worry" or "be upset" if bowels did not move daily.

\section{Discussion}

The investigation of risk factors for constipation in a community based sample of elderly people has proved difficult, but not because of any unwillingness of the subjects to discuss the topic-in fact the response rate to the study was $90 \%$. Rather, the difficulties have arisen because the condition is so amenable to self treatment. We have found, as did Whitehead et al, ${ }^{1}$ that there is a significant group of elderly people who regard themselves as constipated but whose bowels move at least every two days. We found this group were higher users of laxatives than the rest of the sample and they were also more likely to modify their diet so that they were taking foods to increase bowel activity. This group is a problem when determining factors associated with constipation, because included in it are those who would be genuinely constipated were they not to take laxatives or modify their diet, as well as those whose bowels would very likely move normally and frequently if left alone. Frequent laxative use may have been a lifelong habit and whether or not constipation was originally a significant problem is difficult if not impossible to determine.

We have therefore used a rigorous definition of constipation, namely a bowel movement only every three days or less frequently, and have excluded from the comparison group those sub- 
jects who took regular laxatives. Women were more likely than men to be constipated and the sex difference was not due to the women in the sample having a higher mean age. This sex difference has also been found in younger populations. ${ }^{910} \mathrm{Per}-$ sistent severe constipation seems much more likely in younger women than men ${ }^{11} 12$ and has been attributed in part to inability to relax the pelvic floor. ${ }^{12} \mathrm{~A}$ hormonal basis through progesterone and motilin has also been suggested, but this does not seem applicable in old age unless the chronic constipation in young life has led to excessive laxative use with secondary changes in the myenteric plexus.

The prevalence of constipation increased with age, but there is no evidence that whole gut transit time is greater in old people $\mathrm{e}^{13}$ and the increase in constipation with age may well be due to an accumulation of adverse factors including illness and medications affecting gut motility and defaecation. In people attending a day hospital Donald $e t a l^{3}$ found arthritis and immobility to be more common in those who were constipated. The number of chronic illnesses and frequency of medications have also been associated with increasing constipation in elderly women. ${ }^{1}$ There was an association between constipation and impairment in activities of daily living and lack of exercise. These variables may be markers of frailty and the end result of an accumulation of health problems. The constipation may be another consequence of this poor physical state resulting from the combination of age and illness.

Drugs which can be constipating were used twice as commonly by those who were constipated as by those with normal bowel activity, and may have been an important contributing factor in about one quarter of those with infrequent bowel motions. Women were more likely than men to be on these agents and this may account for some of the sex difference in the prevalence of constipation.

Low intake of dietary fibre, fruit, vegetables, bread and cereal, or fluid intake were not found to contribute to constipation. The two most likely reasons for this are that overall the elderly people in Mosgiel had very satisfactory diets, as shown by our 10th percentile levels, and that those who considered themselves as being at risk of constipation modified their diets appropriately.

The group who considered themselves constipated but whose bowels moved regularly were more likely to consider themselves to be in poor health compared with their contemporaries and were more likely to be taking hypnotics. In this "subjectively constipated" group there were a few who were very concerned if their bowels did not move daily and who may be unnecessarily concerned about their health and body functions.

Infrequent motions, the need to strain at stool, and the feeling of being moderately or severely constipated were found to be common in this sample of elderly people. Laxative use was high and so also was modification of diet to increase fruit and fibre. Some of the concern about bowels may well be a residual effect from the upbringing of this generation, but the increase in illness, frailty and inactivity, and the use of constipating drugs in old age can put elderly people at increased risk of genuine and distressing symptoms from constipation.

We wish to acknowledge the continuing support of the elderly people in Mosgiel, the general practitioners of the Mosgiel Health Centre, our research nurse Mrs Joyce Fitzgerald, and statistician Mrs Stephanie McConnon.

This study was supported by the Health Research Council of New Zealand and the New Zealand Lottery Board.

1 Whitehead WE, Drinkwater D, Cheskin LJ, Heller BR Schuster MM. Constipation in the elderly living at home. $f$ Am Geriatr Soc 1989; 37: 423-9.

Kallman H. Constipation in the elderly. Am Fam Physicia 1983; 27: 179-84.

3 Donald IP, Smith RG, Cruikshank JG, Elton RA, Stoddard ME. A study of constipation in the elderly living at home. Gerontology 1985; 31: 112-8.

4 Campbell AJ, Borrie MJ. Reference values for upper arm anthropometric measurements for a New Zealand community sample of subjects 70 years and over. Hum Biol 1988; 60: 587-98.

5 Yesavage JA, Brink TL, Rose TL, et al. Development and validation of a geriatric depression screening scale: a preliminary report. $\mathcal{F}$ Psychiatr Res $1983 ; 17: 37-49$.

6 Folstein MF, Folstein SE, McHugh PR. "Mini-Mental State": a practical method for grading the cognitive state of State": a practical method for grading the cognitive state of
patients for the clinician. $\mathcal{F}$ Psychiatr Res 1975; 12: 189-98.

patients for the clinician. F Psychiatr Res 1975; 12: 189-98.
7 Lawton MP, Brody EM. Assessment of older people: self maintaining and instrumental activities of daily living. maintaining and instrumental

8 Campbell AJ. Measures to improve the response rate in community based studies of elderly people. $\mathcal{f}$ Clin Exp Gerontol 1986; 8: 41-50.

9 Connell AM, Hilton C, Irvine G, Lennare-Jones JE, Misiewicz JJ. Variation of bowel habit in two population samples. BMF 1965; ii: 1095-9.

10 Moore-Gillon V. Constipation: what does the patient mean? f $R$ Soc Med 1984; 77: 108-10.

11 Read NW, Timms JM, Barfield LJ, Donnelly TC, Bannister JJ. Impairment of defaecation in young women with severe constipation. Gastroenterology 1986; 90: 53-60.

12 Turnbull JK, Lennard-Jones JE, Bartram CI. Failure of rectal expulsion as a cause of constipation: why fibre and laxatives sometimes fail. Lancet 1986; i: 767-9.

13 Barrett JA, Chew D. Disorders of the lower gastrointestinal tract. Rev Clin Gerontol 1991; 1: 119-34. 